\title{
Cost outcome analysis in injury prevention and control: a primer on methods
}

\author{
Ted R Miller, David T Levy
}

Investments in public programs typically are constrained by a desire for fiscal responsibility. Decision makers are interested in knowing if an investment produces desired results less expensively than alternative approaches, or if an investment's benefits exceed its costs. They may want to determine whether a particular program is worthwhile to implement (a prospective approach), or whether a program that has already been implemented has been worth its cost (a retrospective approach). World wide, concerns about health care costs have pressed these issues to the forefront.

Cost outcome analyses generally develop a measure of the cost per positive outcome from an intervention. By expressing outcomes in a common metric, such analyses often clarify murky resource allocation decisions. For example, is it more important to fix the swings, which will prevent five broken arms a year, or the seesaws, which will prevent four sprained ankles and two broken legs a year? Should we flatten the curve on High Street, which will prevent one pedestrian death every four years, or add a shoulder on Rose Street, which will prevent five hospitalizations a year?

Besides helping to compare different interventions, cost outcome analyses help to identify the consequences and costs of a particular intervention. An injury prevention program may not only lead to the avoidance of injury and death and associated medical costs, but also a reduction in property damage, work loss, and pain and suffering. The costs of implementing the program include not only direct expenditures on salary, equipment and space, but also other uncosted resources such as volunteer time or public resources such as police time. Program costs and outcomes may sometimes be broken down into who actually bears the burden: health care providers, potential victims of injury, or taxpayers through additional government costs.

To deal with such challenging questions, three types of cost outcome analyses (table 1) are available:

Cost effectiveness analysis (CEA) expresses the outcome in a convenient and useful measure, for example, per life saved or per scald burn prevented. The findings are normally expressed as ratios, such as the cost per year of life saved or the cost per injury avoided.

Cost utility analysis (CUA) extends cost effectiveness analysis by including different uncosted outcome measures, weighted by a common unit. The common unit is usually a quality adjusted life year, or QALY. ${ }^{1}$ QALYs (and variants, like the World Bank's disability adjusted life years), are scales that value a year in any given health state between death (with value 0 ) and perfect health (with value 1), based on a representative individual's prefer- ences among different health states. QAL reflect not only years of life saved but also the degree of functioning and health during thos years. They do not reliably measure out-of pocket cost savings due to care. Thus, it is generally desirable to subtract these savings (for example, reduced property loss and medical costs savings) from the cost term when computing a cost utility measure.

Cost benefit analysis (CBA) places dollat values on all significant outcomes, including death, pain and suffering, and property loss, 8 that benefits are directly compared with cos in monetary terms. Reporting costs and out comes in a common metric facilitates compasison over diverse programs, and allows tipe benefits to be clearly distinguished from the costs. (A CUA may be translated into a CBA by placing a dollar value on QALYs. ${ }^{2-5}$ )

We describe the steps in a cost outcome analysis, including the choice of perspectige and the injury cost components relevant whe valuing injury prevention. A benefit $\cos t$ analysis of smoke detectors illustrates the methodology. We then discuss common errows in cost outcome analysis, and conclude wifi some recommendations.

Steps in a typical cost outcome analysis Methods for safety benefit cost analysis are described in great depth elsewhere. ${ }^{16-9}$ summarize here for a non-technical audience. The approach includes the following steps:

\section{(1) DEFINE THE INTERVENTION}

Determine the specific program or group $\mathrm{g}$ programs to be evaluated, the target population or populations who are intended to be affected by the different outcomes, and the time horizon over which the costs and benefits are defines.

\section{(2) CHOOSE THE PERSPECTIVE OR}

PERSPECTIVES THE ANALYSIS WILL TAKE

Different decision makers or audiences mary have different perspectives, including that $\mathscr{\text { f }}$ society, society excluding the person wiso caused the injury (for example, a drunk driver), government, or other interest groups. The perspective should be explicitly stated. ${ }^{6}{ }^{10} \mathrm{It}$ त⿱ generally desirable to present a societal pe् spective that takes into account costs arf benefits to all members of society. This perspective is the most relevant for publec decision making. Much of the medical liter ture just estimates the net effect on medicầ1 spending; this constitutes an analysis from the perspective of the health care system or the agencies that finance health care. It ignores the value of the good health produced. 
(3) CHOOSE HOW TO ADJUST FOR DIFFERENT VALUES OF MONEY OVER TIME

When valued at current prices, the value of costs or benefits of an intervention generally increase in time due to price inflation. Therefore, they should be adjusted to prices in a common base year. In addition, costs of an intervention made in the future, or benefits only to be received in the future, are of lesser value, because money can earn interest when invested or deposited in a savings account and because the future is uncertain. Therefore, future costs and benefits should be discounted to their present value. (US courtrooms currently use discount rates between $1 \%$ and $3 \%$ for work losses and ancillary costs, and $0 \%$ for future medical costs. Governments use much larger discount rates, 4-8\%.) Some suggest a discount rate of $3 \%$ for analyses using a societal perspective; our studies use a $2.5 \%$ discount rate. ${ }^{6711}$

\section{(4) ESTIMATE THE COSTS OF THE} INTERVENTION

Direct expenditures at the market price are often used to value resources because this

Table 1 Differences in cost outcome methodologies

\begin{tabular}{lll}
\hline Type of study & Identification of effects & Measurement of effects \\
\hline CEA & $\begin{array}{c}\text { Single effect of interest to alternative } \\
\text { strategies, but achievable to } \\
\text { different degrees }\end{array}$ & $\begin{array}{c}\text { Natural units (for example, life years } \\
\text { gained, days saved, injuries } \\
\text { avoided, accidents prevented) }\end{array}$ \\
CUA & $\begin{array}{l}\text { Single or multiple effect, not } \\
\text { necessarily common to alternative } \\
\text { strategies, and common effects } \\
\text { may be achieved to different } \\
\text { degrees }\end{array}$ & QALYs or healthy days \\
CBA & $\begin{array}{l}\text { Single or multiple effects, not } \\
\text { necessarily common to alternative } \\
\text { strategies, and common effect may } \\
\text { be achieved to different degrees }\end{array}$ & Dollars \\
& &
\end{tabular}

Table 2 Potential cost savings from injury interventions

\begin{tabular}{lll}
\hline Type of cost & Costs included & Measurement \\
\hline $\begin{array}{c}\text { Medical } \\
\text { care costs }\end{array}$ & $\begin{array}{c}\text { Health care expenses due to } \\
\text { personal injury and illness }\end{array}$ & $\begin{array}{c}\text { Payments for hospital and physician care, as } \\
\text { well as rehabilitation, mental health care, } \\
\text { prescriptions, allied health services, and } \\
\text { medical devices. Coroner and premature } \\
\text { burial costs for fatalities, and the costs of } \\
\text { medically related loss compensation through } \\
\text { insurance and the courts also may be } \\
\text { included }\end{array}$
\end{tabular}
Property
damage and $\begin{aligned} & \text { Property damaged or lost } \\ & \text { during the injury incident }\end{aligned}$ loss

Cost of public Increased criminal justice and programs social service expense, reduced welfare payments, and reduced use of emergency services

Lost future work

Work lost by victims and their families, and increased employee recruitment and training costs

Pain, suffering, Value of the pain, suffering, and lost quality of life and lost victims and their families experience due to iniury, illness and death
Value of property damage and of property taken and not recovered, plus administrative costs of processing insurance claims for property losses

Costs of emergency services, the criminal justice system, social services, and of administering payments under disability insurance and welfare programs. Emergency services include police, fire, ambulance, and helicopter services. Some studies include emergency medical transport costs in medical costs instead

Wages, fringe benefits, housework, and possibily school days lost by the victims and their families, as well as life insurance and workers' compensation claims processing costs. Also included is the value of productivity lost by coworkers and supervisors recruiting and training replacements for disabled workers

For non-fatal injury and illness, the value is based on jury awards and settlements, or estimated from QALYs lost. For fatalities, the value is computed from the amount people routinely spend to reduce their risk of death information is readily available. Waiting, other lost time, volunteer time, or donated facilities have no monetary value but, because the time and donated facilities could possibly have been used in some other way, for example by another intervention, they have a measurable value. This is computed in terms of opportunity costs by taking the next best possible use of those resources. For example, donated space is costed at its rental value, and volunteer labor is valued at the hourly wage that would be required to obtain the service. Allocation of overhead costs shared with other programs (for example, office space or administrators) and capital costs (for example, for computers or machinery) also require special attention. ${ }^{112} \mathrm{It}$ may be inappropriate to include overhead costs, if, for example, the intervention would not affect administrator's time or the application of machinery to other uses. It is important to include additional, or marginal, cost of implementing the program. The costs included also depend on the perspective of the decision maker; for example, volunteer time may not be relevant from a government perspective.

\section{(5) CHOOSE THE RELEVANT OUTCOMES}

Identify the injuries that the intervention could prevent, and any non-medical outcomes that may be relevant. For example, a traffic safety intervention may reduce property damage or the need for other publicly funded programs (for example, police services). An intervention that reduces handgun availability may also reduce property damage (from fewer robberies) or the need for public programs aimed at criminal sanctions.

When the outcomes are presented in monetary terms (for example, a CBA), the benefits of injury reduction are stated as reduced injury costs. Table 2 presents the costs that may be saved. Injuries often involve loss of work, and generally, involve pain and suffering. Interventions may lead to reduced property damage and public program costs. Of the cost savings, the value of pain and suffering and lost quality of life is the most controversial. Some analyses, such as those using the cost of illness approach, exclude lost quality of life; they simply value the loss of life by lost wages. ${ }^{13}$ Because pain and suffering are estimated less directly than other costs, valuations of reduced pain, suffering, and lost quality of life may be reported separately from other benefits. ${ }^{14}$ (There is a growing trend toward including quality of life in costs in transport analyses in the developed world. ${ }^{15}$ )

We generally classify benefits into three categories: medical, other tangible or monetary, and quality of life. Sometimes, non-injury costs, such as property damage avoided or travel time savings are distinguished. The outcomes included depend on the perspective. For example, social costs include all those in table 2, except for the non-administrative portion of welfare and other transfer payments. The government perspective includes transfer payments, government medical care payments, and lost tax payments from individuals and 
businesses. It excludes most property damage, other medical payments, lost wages, and pain and suffering.

\section{(6) ESTIMATE THE EFFECT OF THE} INTERVENTION ON OUTCOMES

The effectiveness estimate is often based on the percentage reduction in incidence or harm. The effects are generally estimated using statistical analyses, but may be inferred from studies of similar programs by others. The incidence of a particular outcome often depends on the percentage of cases attributable to the problem addressed by the intervention, for example, drunk driving.

(7) CALCULATE THE BENEFITS

The outcomes reflect the savings from the intervention. The benefits are the estimated number of injuries or incidents prevented, the associated QALYs, or cost savings. When outcomes are expressed as a percentage reduction in incidence, the benefits are estimated by multiplying the total incidence (or costs or QALYs) in the target population before the intervention by this percentage.

(8) COMPUTE THE COST OUTCOME RATIO For CBA, the cost outcome ratio is obtained by dividing expected benefits by expected costs. This ratio is useful for comparing programs. It may also be useful to compute the difference between benefits and costs-a measure of the net savings (or losses) from the program. For CEA and CUA, the net program costs (costs minus dollar benefits) is divided by the outcome to yield a measure such as cost per crash averted, or cost per QALY.

\section{(9) DESCRIBE ANY UNQUANTIFIED COSTS AND} BENEFITS

Potential costs and benefits outside the time frame of the analysis, affecting other than the target population, or from more widespread adoption of the intervention need to be considered, even if a dollar value cannot be placed on these effects.

(10) ANALYZE WHO BENEFITS AND WHO PAYS Estimate who bears the costs of the intervention, and who gets the benefits (for example, government, insurers).

\section{(11) CONDUCT A SENSITIVITY ANALYSIS}

Show how the results vary when parameters (for example, the discount rate, intervention effectiveness) change. It also may be useful to show how the estimates depend upon assumptions made in deriving the effects of the intervention, for example, that the reduction in one type of harmful behavior, such as drinking while driving, does not lead to other types of harmful behavior, such as illicit drug use.
An example: a benefit cost analysis of a smoke detector program

This section presents, as an example, a previously unpublished benefit cost analysis of a program to encourage the use of smok detectors. It follows the steps listed in the preceding section.

\section{(1) DEFINE THE INTERVENTION}

The intervention estimates the return on the retail purchase, installation, and maintenance of smoke detectors for all US homes (or ca typical US home). An average home require 1.6 smoke detectors. We assume these are used for five years (the typical warranty period, but lower than the detector's 12 year usefua life). ${ }^{1617}$

(2) WHAT IS THE PERSPECTIVE?

We examine smoke detector purchase from societal perspective and document the effect of insurance costs.

(3) HOW ARE FUTURE VALUES ADJUSTED?

Benefits and costs are projected over a five yeå period, and are, therefore, discounted at $2.5 \%$. (This rate lies at the conservative end of the 19 $3 \%$ range the US Supreme Court consider unassailable in determining tort liability come pensation.) Benefits are measured in currer dollars, so need not be adjusted for inflation.

(4) WHAT DOES A SMOKE DETECTOR COST? 尔 Smoke detector costs include the purchase price, maintenance cost, and time spee purchasing, buying batteries and other main tenance. In the US, 1.6 smoke detectors cost $\$ 12$ including batteries. Replacement batterie in years $2-5$ cost $\$ 3$ per year for 1.6 smoke detectors. In addition, we estimate 1.5 hours to buy and install the detectors, and 10 minutés yearly to buy and install replacement batteries. Time spent on home repair and maintenance like other household work time, typically is valued at the hourly wages that people pay if they hire someone. ${ }^{19}$ From US Department of Labor statistics, the average hourly wage for home repair is $\$ 9.24$ (in 1994 dollars). With five year life, the present value of detector costs per home is $\$ 42.90$. This consists of $\$ 12$ purchase price plus $\$ 13.86$ (1.5 hours $\times \$ 9.24)^{\circ}$ for installation plus $\$ 17.04$-the present value over years $2-5$ of a $\$ 3$ annual battery purchase plus $\$ 9.24 / 6$ for battery purchase and installa tion. (Undiscounted, the battery related costis are \$18.16.)

Installing smoke detectors in 90.9 millio US homes would cost about $\$ 3.9$ billion. Thi includes $\$ 2.15$ billion in out-of-pocket costs and time valued at $\$ 1.75$ billion.

(5) HOW LARGE IS THE RESIDENTIAL FIRE TOLL?

IN 1991, US Vital Statistics recorded 5317 deaths in residential fires (from burns, anoxia, 
or other injuries). Miller et al estimated nonfatal fire injury counts by level of medical treatment from the National Fire Incident Reporting System, the National Hospital Discharge Survey (NHDS), and the National Electronic Injury Surveillance System. ${ }^{20}$ As table 3 reports, an estimated 266000 fire survivors were injured, of whom 14100 were admitted to hospitals.

\section{(6) WHAT DO RESIDENTIAL FIRES AND FIRE}

\section{INJURIES COST?}

Savings in fire costs are the potential benefits from the intervention. The estimated cost per residential fire burn victim (table 3 ) is based on a model developed in a report to Congress on cigarette fire costs. ${ }^{20}$ Non-hospital medical costs were based on the 1987 National Medical Expenditure Survey (NMES) and third party payer data. Hospital costs used NMES data and Worker's Compensation payments data. NHDS data from 1984-90 on length of stay were used to estimate costs by body part burned and degree of burn. Costs for injuries other than burns and anoxia are from the databook on non-fatal injury. ${ }^{21}$

To assess how burn and anoxia costs vary by cause, we used 1990 hospital discharge data from California, where causes are coded for more than $90 \%$ of injuries. We also used data from burn centers, where more detailed causes are recorded. Serious cases are triaged to burn centers; the data cover all centers serving Delaware, New Jersey, and the eastern half of Pennsylvania, and represent about $40 \%$ of burn hospitalizations in that area.

Wage and housework losses were modeled using National Health Interview Survey data.
A total of 397 jury verdicts were used to value pain, suffering, and lost quality of life associated with burns by cause and severity. Property damage and loss are based on national fire statistics.

Estimated total annual residential fire losses are $\$ 34.3$ billion (in 1994 dollars). This includes $\$ 0.7$ billion for medical care, $\$ 5.5$ billion for other tangible injury costs, $\$ 22.0$ billion for pain and suffering, and $\$ 6.1$ billion for property damage (table 4 ).

\section{(7) HOW EFFECTIVE ARE SMOKE}

\section{DETECTORS}

Using time series analysis, Garbacz estimated smoke detector effectiveness against residential fire burn deaths to be $15.5 \% .^{22}$ We assume detectors reduced non-fatal injuries proportionally. Gabacz's estimate attributes most of the precipitous decline in fire deaths after the introduction of smoke detectors to other factors and is, therefore, conservative. In contrast, National Bureau of Standards (NBS) engineering estimates suggest detectors are $45 \%$ effective against deaths and $30 \%$ effective against non-fatal injuries. ${ }^{23}$ This is close to Hall's estimate of roughly $50 \%$ effectiveness against fatalities. ${ }^{24}$

The odds of a residential fatality in a home without smoke detectors is 10.5 times the odds with detectors. ${ }^{16}$ This implies $90 \%$ effectiveness, but fails to control for any factors that make homes without detectors more fire prone. We computed benefit cost ratios using both the $\mathrm{Garbacz}^{22}$ and $\mathrm{NBS}^{23}$ estimates, and assessed the added savings assuming detectors were $10 \%$ effective against property damage.

(8) HOW MANY DEATHS AND INJURIES CAN SMOKE DETECTORS PREVENT?

Incidence data were from a time when about $88 \%$ of homes had smoke detectors. ${ }^{16} \mathrm{~A}$ national survey with professional operability testing found $81.2 \%$ of the homes with smoke detectors had at least one operational unit. ${ }^{16}$ This means $71.4 \%$ of all homes have at least one working detector. To compute losses for homes without any smoke detectors, we divide 1991 losses by the fraction of losses not averted at the $71.4 \%$ usage rate $(1-0.714$ with working detectors $\times$ average effectiveness).

From the Garbacz ${ }^{22}$ effectiveness estimates, without detectors the annual fire toll would be $\$ 31.8$ billion ( $\$ 0.8$ billion in medical costs, $\$ 6.2$ billion in other tangible costs, and $\$ 24.8$ billion in lost quality of life). From the $\mathrm{NBS}^{23}$ effectiveness estimates and computing fatal and non-fatal costs separately, the annual toll would be $\$ 38.9$ billion ( $\$ 0.9$ billion in medical costs, $\$ 7.8$ billion in other tangible costs, and $\$ 30.2$ billion in lost quality of life). Assuming detectors reduce also property losses, property losses would total $\$ 6.5$ billion. 
(9) WHAT NET COST SAVINGS, TOTAL AND PER HOME DETECTOR, RESULT FROM SMOKE DETECTOR USE?

Universal detector installation, assuming $81.2 \%$ are operational, would reduce the annual cost by $\$ 4$ billion, ${ }^{22}$ or by $\$ 12$ billion. ${ }^{23}$ If all detectors were operational, another $\$ 1.0-2.9$ billion would be saved. Property damage reductions add $\$ 0.5$ billion to the savings.

Thus, the estimated cost savings per detector are $\$ 210-636$. This includes $\$ 6-13$ in medical spending, $\$ 41-137$ in other tangible costs, and quality of life gains valued at $\$ 163$ 486. (The total excludes $\$ 28$ in possible property damage savings.) Thus, the benefit cost ratio for a detector is 5.5-15.5 (210/42.90 to $636 / 42.90$ ). Ignoring time costs and quality of life benefits but including property damage, the ratio of tangible benefits to out-of-pocket costs is $3.0-7.5(74 / 23.60$ to $178 / 23.60)$.

\section{(10) WHAT UNCOSTED OUTCOMES RESULT?}

- Parents will spend less time and expense caring for injured children.

- Lawyers will file fewer lawsuits seeking compensation for fire injuries.

- Some smoke detectors will trigger unnecessarily (for example, when an attended frying pan smokes).

- Pets will be saved from death and injury.

\section{(11) HOW WILL INSURANCE PAYMENTS CHANGE?}

Insurers, public and private, will save almost all of the medical payments, claims processing expenses, and legal expenses, an estimated $\$ 8-21$ per detector. If property damage is reduced, home insurance claims may drop by an additional $\$ 25$ per detector, or $\$ 45$ per home.

\section{(12) HOW SENSITIVE ARE THE RESULTS?}

The estimated return is sensitive to the detector's effectiveness, the per cent of installed detectors that are operating, and the discount rate. Even at the most conservative effectiveness level, however, the tangible returns alone are several times the costs.

\section{Discussion}

Some of the basic problems encountered in trying to understand and interpret cost outcome analyses arise because the perspective of the analysis, the intervention being analyzed, the target population, the time horizon, or assumptions used in developing any models, have not been clearly defined. For example, the only data on outcomes may be from a trauma center/registry, rarely a representative source. Registries ignore the effects of cases in other settings; for example, less severe burns may increase in other hospitals as severe burn victims in burn centers covered by the registry are reduced.

In analyzing the costs of an intervention, certain costs may be omitted. These include overhead costs for offices and administration, fringe payments for labor, volunteer time, and maintenance on machines. Other problems are. more mundane, such as the failure to discount benefits or costs that arise in different years. ?

When determining medical care costs or savings, charges are sometimes not distin $=$ guished from actual payments. For most US? medical claims, the costs are negotiated and differ considerably from the listed charges. I that is the case, it should be made explicit, ano a discussion should follow on whether future costs also will depend upon negotiations.

The size of benefits may also depend on the way data are collected. For example, police world wide have datasets on assualt and rapeo cases. Counts from such datasets understate incidence because many crimes are not re $\mathrm{r}_{\tilde{j}}$ ported to the police. Highway crashes also areळo under-reported; and injured victims are under윽 counted or misclassified in reported crashes(because the officer does not examine the victim). In the US, alcohol use is not identifie of in police reports for one third to one half oB drunk driving crashes involving a non-fatab injury, while police reports tend to overesti mate belt use. ${ }^{25}$

The list of benefits may be too narrow:Omitting non-medical or quality of life outcomes cheats the program of its rightful credit In particular, work and quality of life gains, often make up a large portion of benefits from कo social perspective. From a governement per $\cong$ spective, transfer payments may be important

The extent of benefits may also be under stated because the analysis is limited to shor term effects. For example, parent counseling with the American Academy of Pediatric TIPP program for a firstborn my lead to changes in parent safety practices for a secon child without further counseling. ${ }^{26}$ On the other hand, prospective analysis may fail to consider implementation delays or failure to implement. The benefits estimate also may be exaggerated by failure to adjust for non-use of misuse. An unbuckled child safety seat or smoke detector with a dead battery offers no protection.

Care is needed in reporting and interpreting cost outcome results. Suppose our CBA of smoke detectors stressed the dollars saved pees dollar invested rather than per detector pur $N$ chased. This approach could mislead thosen detector distribution programs that were pay $-\overline{-}$ ing more (or less) for their detector than the price in our analysis.

To compare cost outcome results in the sames unit of effectiveness, analysts must be aware that factors such as population characteristics, the scale of the intervention, and the presences of other programs could influence the results $\stackrel{\mathbb{Q}}{\mathbb{Q}}$ For example, gender, age, ethnicity, environ-0 mental conditions, or condition specific risk factors may predispose people to a particulaio problem. Consequently, the costs, as well as the effectiveness, of the intervention will vary? across populations, creating differences in cost outcome ratios. If possible, those evaluating an intervention that serves groups of people with 
different characteristics should calculate population specific cost outcome ratios in addition to a total ratio. In addition, the analysis could depend on the scale of the intervention. For example, a small program that saves one life could have a higher cost effectiveness ratio than a large program that saves many. In developing a comprehensive safety approach, it is also critical to understand how interventions interact. For example, the effectiveness of a sobriety checkpoint program will be reduced if vigorous enforcement of laws against sales to minors reduces the number of drunk drivers on the road.

When evaluating alternatives in a resource constrained world, the highest benefit cost ratio is not necessarily the best choice. An alternative may yield larger total benefits but at a slightly higher cost per unit of safety. When evaluating related alternatives, the incremental, rather than total cost and benefit, should be evaluated. The benefits of provisional licensing of youth with a curfew at $10 \mathrm{pm}$ may exceed its costs, but the benefits of a $10 \mathrm{pm}$ curfew relative to a $12 \mathrm{pm}$ curfew are smaller than the incremented costs. ${ }^{11}$

\section{Conclusion}

Cost outcome analysis is often used to justify a particular program to government decision makers, or to managed care providers. Perhaps more important is its value in guiding choices among alternative interventions in a resource constrained world. To compare programs or base decisions on cost outcome analysis for a particular program, cost outcome analyses need to maintain a high level of quality. ${ }^{16710}$ The inclusion of a common perspective, such as the societal perspective, and common cost categories in all analyses, facilitates comparison between interventions.

This research was supported by the Office of Maternal and Child Health, DHHS under Children's Safety Network grant MCJ-113A36-01 and by the National Institute on Alcohol Abuse and Alcoholism under grant AA09812-02.

1 Drummond MF, Stoddart GL, Torrance GW. Methods for the economic evaluation of health care programs. New York City: Oxford University Press, 1987.

2 Miller TC, Calhoun C, Arthur WB. Utility-adjusted impairment yeras: a low-cost approach to morbidity valuation. Estimating and valuing morbidity in a policy valuation. Estimating and valuing morbidity in a policy context. Proceedings of a June 1989 AERE Workshop.
EPA-230-08-89-065. Washington, DC: US Environmen- tal Protection Agency.

3 Miller TR. Societal costs of transportation crashes. In: Greene DL, Jones DW, eds. Proceedings of Bureau of Transportation statistics conference on the social costs of transportation. New York: Springer-Verlag, 1997 (in transporta

4 Miller TR Injury cost estimation: a pain in the neck. In: Ryan A, ed. Proceedings of conference on measuring the
burden of injury. Adelaide: University of Western Ausburden of injur

5 French MT, Masukopf JA, Teague JL, Roland J. Estimating the dollar value of health outcomes from drug abuse interventions. Med Care 1996; 34: 890-910.

6 Gold MR, Siegel JE, Russell LB, Weinstein MC, eds. Costeffectiveness in health and medicine. New York: Oxford University Press, 1996.

7 Haddix AC, Teutsch SM, Shaffer PA, Dunet DO. Prevention effectiveness, a guide to decision analysis and economic evaluation. New York: Oxford University Press, 1996.

8 Miller TR, Hunter W, Waller P, Whiting B, Whitman R. Development of a value criteria methodology for assessing highway systems cost-effectiveness. Spring

9 Miller TR. Benefit-cost analysis: past and future directions. In Stammer RE, ed. Highway safety: at the crossroads. New York, NY: American Society of Civil Engineers, 1988.

10 Udvarhelyi SI, Colditz GA, Rai A, Epstein AM. Costeffectiveness and cost-benefit analyses in the medical literature - are the methods being used correctly? Ann Intern Med 1992; 116: 238-44.

11 Miller TR, Lestina DC, Spicer RS. Highway crash costs in the United States by driver age, blood alcohol level, victim age, and restraint use. 40th Proceedings of the Association for the Advancement of Automotive Medicine. Association for the Advancement of Autom

12 Thompson M. Benefit-cost analysis for program evaluation. Beverly Hills, CA: Sage Publications, 1980.

13 Rice DP, Kelman S, Miller LS, Dunmeyer S. The economic costs of alcohol and drug abuse and mental illness: 1985. Rockville, MD: Alcohol, Drug Abuse, and Mental Health Administration, US Department of Health and Human Services, 1990.

14 Miller TR. The plausible range for the value of life: red herrings among the mackerel. fournal of Forensic Economics 1990; 3(3): $17-40$.

15 Elvik R. An analysis of official economic valuations of accident fatalities in 20 motorized countries. Accid Anal Prev 1995; 27: 237-47.

16 Smith CL. Smoke detector operability survey: report on findings. Bethesda, MD: US Consumer Product Safety CommisBethesda,

17 Evans S. How long things last. The Washington Post. Home section, 20 March 1997: 10-2.

18 US Supreme Court. Jones and Laughlin Steel Corp v Pfeifer. 103 Supreme Court Reporter. Washington, DC, 1983: $2541-58$.

19 Murphy M. The value of household work in the United States, 1976. Measuring nonmarket economic activity. Bureau of Economic Analysis Working Paper No 2 Washington DC: US Department of Commerce, 1982: 23-41.

20 Miller TR, Brigham P, Cohen M, et al. Estimating the costs to society of cigarette fire injuries. Report of congress in response to the fire safe cigarette act of 1990 . Washington, response to the fire safe cigarette act of 1990 . Washington,

21 Miller TR, Pindus NM, Douglass JB, Rossman SB. Nonfatal injury incidence, costs, and consequences: a data book. Washington, DC: Urban Institute Press, 1995.

22 Garbacz C. Smoke detector effectiveness and the value of saving a life. Economic Letters 1989; 31: 281-6.

23 Dardis $R$. The value of life: new evidence from the marketplace. American Economic Review 1980; 70 1077-82.

24 Hall JR. A decade of detectors. Fire fournal September 1985; 79: $37-43 / 78$

25 Miller TR, Blincoe L. Incidence and cost of alcoholinvolved crashes in the United States. Accid Anal Prev 1994; 26: 58 .

26 Miller TR, Galbraith MS. Injury prevention counseling by pediatricians: a benefit-cost comparison. Pediatrics 1995; 96: $1-4$.

\section{Burns due to head lice treatment}

Dr el Habashy, a senior house officer in the burns unit at Selly Oak Hospital, Birmingham, reported that a 7 year old girl came to the unit with burns to her face covering $3 \%$ of her total body surface area. She had been treated with malathion (Prioderm) for her hair lice. The fumes from the lotion made her panic, and as she ran past the lit gas cooker at a distance of $1 \mathrm{~m}$ a trail of fire followed her and caused severe burns. Prioderm contains isopropyl alcohol and should be applied in a well ventilated room well away from any naked flames (BMF 19 July 1997, p 198). 